\title{
A Document Of Debatable Value - A Case Study Into The Use Of Master-Pilot Exchange Documentation In Selected UK Ports
}

\author{
Richard Wild FRIN and Kevin Constable MSc MNI
}

(E-mail: richardjwild@gmail.com)

\begin{abstract}
This paper will demonstrate that the Master Pilot Exchange (MPX) is a document of debatable value in pilotage waters. The MPX exists in many formats which are designed to reflect local navigational challenges and port requirements. A generic form exists which can aid the design of local MPX forms. Both the generic and port MPX forms may require the recording of information that has a neutral outcome on the planned act of pilotage. Analysis of significant incidents suggests that investigation recommendations are not consistently reflected in MPX forms and there is a gap between what should be recorded and reality.
\end{abstract}
KEYWORDS
1. Pilotage.
2. Generic MPX.
3. Port Specific MPX.
4. MPX Attributes.

Submitted: 19 November 2012. Accepted: 29 January 2013. First published online: 14 March 2013.

1. INTRODUCTION. Pilotage is as an essential skill required when navigating in estuaries and manoeuvering in confined waters and ports, thus it is an integral component of marine navigation. Around the world there are many variants of pilotage in regard to the nature of the work, the regulation of the work and the employment conditions of the pilots. However, one constant in this is the relationship between Master and Pilot and the information exchange that must take place in order to enable them to work in partnership. There must be a plan of where the ship will go and a discussion as to how this plan can be safely executed. Much depends on the information exchange and discussion, the Master Pilot Exchange (MPX), which takes place. Indeed, recent post-incident investigations have identified that a failure in this process can lead to an error chain resulting in an incident. A notable example is the collision of the container ship Cosco Busan with the San Francisco-Oakland Bridge (USCG, 2009).

The MPX process can be divided into two elements: an exchange of technical information and the non-technical aspects such as the interaction of the Bridge Team with the Pilot. The successful completion of an act of pilotage is dependent on both 
these elements being undertaken effectively. However, the success of each is inextricably linked to the ability of individuals to communicate and have meaningful dialogue. This paper focuses on the technical aspects rather than what are often called human factors. This is because the aim is to demonstrate that poorly designed documentation, while it may be adequate to exchange and record technical information such as the Under Keel Clearance (UKC), does not facilitate the subsequent non-technical discussions between the Master and Pilot.

Technical information exchange has two originators: shore-to-ship and shipto-shore. The former can encompass details of the berth, UKC calculations and an indicative route. The latter will concern, primarily, the dimensions of the ship, including her draft, and manoeuvering details such as the type and number of propellers, and, if fitted, the power of thruster(s). There are industry standards as to the minimum information that should be shared and these are discussed in the literature review.

\section{LITERATURE REVIEW.}

2.1. Key Search. A survey by the International Group of Protection and Indemnity clubs indicates that there is an average of more than 50 claims p.a. costing over US\$100,000 relating to damage incidents incurred when a Pilot has been embarked. It should be noted that cases of machinery breakdown are included within these figures. Nevertheless, this survey resulted in the following recommendation: "Better or further training or briefing in Bridge Team Management with the Pilot on board, especially in relation to passage planning berth-to-berth and the ability of the Bridge Team to be in a position to judge when there is a departure from the passage plan when berthing or unberthing. Reiterate the Master/Pilot information exchange process." (IGP\&I, 2004, p. 2)

In addition, the need to use two check lists, shore-to-ship and ship-to-shore, was highlighted. Promulgation of the existence of these generic check lists followed. It is the second of these check lists, invariably supplied by the Pilot, that is under consideration.

2.2. Industry standards and benchmarks. The International Chamber of Shipping has produced what could be said to be the seminal guide on Bridge Procedures (The Bridge Procedures Guide, 2007). This Guide contains an indicative, or generic, shoreto-ship checklist (Annex A.1). Mutual insurance organisations, which are commonly known as Protection and Indemnity clubs (P\&I) have also produced guidance and an example of such is 'A Master's Guide to Berthing' (Murdoch et al., 2004). The guide advises that "the relationship between the Master and the Pilot is fraught with potential difficulties and conflict" (Murdoch et al., 2004, p. 32). In addition, three organisations representing tanker owners have produced guidance entitled 'International Best Practices for Maritime Pilotage' (Intertanko, OCIMF and ICS, 2002). All these publications offer broad detail on the technical exchange and discussion that should take place. The latter states that, as a minimum, "communications procedures, sufficient details of the prospective berth and routing information to enable the Master to prepare a provisional passage plan to the berth prior to arrival" should be provided (Intertanko, OCIMF and ICS, 2002, p. 3). It is recognised that a final agreement of the plan can only take place after the Pilot boards the ship. 
The guide states that the Master should "not commit his ship to the passage until satisfied with the plan" (Intertanko, OCIMF and ICS, 2002, p. 4).

2.3. Investigation reports. There have been a number of high profile incidents where the resulting investigation report has included comment on the manner in which the Master/Pilot exchange was conducted. Three such occasions are: the Sichem Melbourne (MAIB, 2008), Cosco Busan (USCG, 2009) and the Vallermosa (MAIB, 2009). Although none of these incidents caused pollution on the scale of Sea Empress (MAIB, 1997), the potential for environmentally damaging incidents is clearly ever present. Such reports are a rich source of recommendations in respect of the Master/ Pilot relationship.

2.4. Addressing human error by paperwork engineering. The aviation industry has had concerns about the impact of human error on operations for many years. In 1993 NASA identified a need to approach the management of human error by means other than a regime of training programs and standardised procedures. One of the proposed remedies was intervention through better documentation. This can be described as the use of technical methods to intervene in non-technical arenas. Of significance is the need to differentiate between flight (or passage) specific information and administrative information. It is important to improve the design of paperwork so that it is compatible with the task (Wiener, 1993). This includes ensuring that documents are completed logically, focussing dialogue in both technical and nontechnical areas. Documents can be used to trigger discussions on areas where human error has been a cause of incidents in the past. For example, if a regulation regarding speed is ignored, an incident could result. Similarly, if a swinging area is not clear when a regulation demands that it should be, the rule needs to be shared so that one individual does not make a flawed judgment call and decide to swing the ship.

\section{Aims, OBJECTIVES, METhodology AND SAMPLing.}

The aim of this research was to determine whether there are differences between the benchmark Master Pilot Exchange (MPX) format and the range of forms used in a sample of UK commercial ports today by comparing the benchmark MPX form with analysis of three significant investigation reports. The objectives were to quantify the MPX into themes and categories and compare these with source material. A mixedmethod research scheme was chosen to facilitate quantitative analysis of the attributes to determine trends. Appropriate qualitative codes were applied to the attributes as themes and categories emerged.

The sample included the full spectrum of ship types: tankers (both gas and wet cargoes), passenger ships, ro-ro and ro-pax vessels, container ships, bulk carriers and specialist activity ships (such as dive-support and other dynamic-positioning capable vessels). The UK sample profile also contains a full range of navigational challenges: open-water, estuarial, narrow channel and river navigation, and harbour and lock work.

A request was sent to 37 UK ports, of which 16 replied with a copy of the MPX form currently in use. It is possible that some of the minor ports do not use a MPX form.

4. FINDINGS AND ANALYSIS. The benchmark or generic MPX form (International Chamber of Shipping, 2007) has provision for 36 items of information 
or attributes to be recorded. Qualitative categorisation of this generic form and the 16 sampled UK port MPX forms indicates that there are seven themes, each with further sub-categories, as follows:

4.1 Ship information

- Dimensions.

- Propulsion.

- Navigation equipment.

- Defect reporting.

4.2 Passage planning

- Sailing directions.

- Passage timing with reference to critical points.

- Indicative route.

- Meteorological conditions.

- Abort points.

\subsection{Berth details}

- Dimensions.

- Mooring requirements.

- Manoeuvering on or off the berth.

\subsection{Communications}

- Internal.

- External.

4.5 Tidal, current and UKC information

- Height.

- Rate and Direction.

- Static.

- Dynamic.

- Other allowances such as siltation.

4.6 Towage information

- Details of tugs.

- Compulsory towage requirements.

- Tug use and disposition.

\subsection{Ancillary information}

- Byelaws and notices provision.

- Dangerous goods or hazardous cargo.

- Manning and Bridge support requirements.

- Security notification.

The most noteworthy finding was that none of the port MPX forms offered all the 36 attributes in the generic form. The greatest number of attribute matches was 34 , the 
least compliant was 8 and the average compliance was 21 (nearest integer). The results are contained within Table 1.

It is also significant that the generic form does not suggest the use of a signature block, but all ports, except one, included a signature block on their document. Two ports issued 'sailing directions' with an emphasis on guidance to the Master of any ship as opposed to an agreed plan for a specific ship and act of pilotage. These two MPX forms offered a very different solution to the other 16 because the customary format, with a range of boxes to be filled-in with information, is not used. For example, neither the ship's name nor its draft are recorded. A chartlet, in conjunction with both routeing and monitoring advice, is supplied by the Pilot to the ship. This is a different approach and could be said to be consistent with the way that a Pilot offers advice to the Master. However, in the UK, the status of the Pilot is clarified in law, and the Pilot has to be given the conduct (or con) of the ship in order to carry out his duties.

Investigation reports from three significant incidents were analysed, focussing on the navigational aspects and the Master/Pilot exchange. Therefore, failures of outside agencies, such as VTS activity, personal issues, or harbour authorities in respect of port procedures, are beyond the scope of this research. Although intervention by outside agencies may have stopped the error chain and thus prevented the incident, significant points of failure on the ships had already occurred. In the case of the Vallermosa, for example, excessive speed at the abort point was a causative fact. However, although the speed was in breach of port regulations, no warnings were issued by VTS and the Master was unaware of the regulation, thus, no interventions were made.

Table 2 shows the seven themes of the generic MPX and an asterisk indicates how many of the three investigation reports analysed identified that there was a causative failure in the theme. For example, the absence of agreement on a comprehensive passage plan between the Master and Pilot is common to all three reports. Each port is shown in the columns A to P and there is an indication of that port's MPX compliance $(\checkmark)$ with the theme. Port A does not have provision for recording agreement of the passage plan, but port B does. The final column shows the compliance of all the ports, expressed as a percentage. For example, one in four ports has provision to record an abort point on the MPX.

The aspect of neutral attributes was also considered. The omission, or poor execution, of certain critical attributes during the MPX process were contributory factors in some or all of the incidents. However, the process of recording other information may have played no part in the incident. In short, although certain information was not shared, it is suggested that the outcome would have been the same. If the generic MPX is taken as the benchmark (and it lists more attributes than any of the port MPX forms), and a comparison made with the significant investigation findings, an assessment of neutral-impact attributes can be made. Table 2 shows that 3 attributes from the generic MPX were identified as a point of failure in the investigations: manning requirements, indicative route and the identification of an abort point. The other 33 attributes on the generic MPX had a neutral effect on the incident.

5. SUMMARY OF FINDINGS. The generic Master Pilot Exchange (MPX) form has three attributes matching with the seven significant points of failure 
Table 1. Summary of Master/Pilot document attributes.

\begin{tabular}{lrrrrrrrrrrrrrrrrrr}
\hline Port & Generic & A & B & C & D & E & F & G & H & I & J & K & L & M & N & O & P & Mean \\
\hline Ship Information & 17 & 4 & 7 & 0 & 1 & 14 & 6 & 1 & 12 & 2 & 7 & 4 & 11 & 2 & 4 & 5 & 6 & 5 \\
Passage Planning & 5 & 2 & 3 & 2 & 7 & 3 & 4 & 7 & 6 & 4 & 5 & 6 & 2 & 6 & 3 & 5 & 7 & 5 \\
Berth Detail & 2 & 1 & 0 & 3 & 4 & 3 & 4 & 8 & 1 & 4 & 1 & 4 & 2 & 4 & 1 & 3 & 7 & 3 \\
Communications & 2 & 0 & 0 & 1 & 2 & 5 & 2 & 1 & 2 & 0 & 1 & 2 & 0 & 1 & 1 & 2 & 1 & 1 \\
Tide and UKC Information & 3 & 3 & 3 & 1 & 2 & 2 & 5 & 3 & 2 & 2 & 5 & 3 & 2 & 3 & 2 & 5 & 2 & 3 \\
Towage & 3 & 1 & 2 & 1 & 1 & 3 & 1 & 2 & 1 & 2 & 2 & 1 & 0 & 1 & 1 & 3 & 3 & 2 \\
Ancillary Information & 4 & 0 & 6 & 0 & 4 & 4 & 4 & 3 & 4 & 4 & 6 & 4 & 3 & 2 & 2 & 6 & 5 & 4 \\
Total matches & $\mathbf{3 6}$ & $\mathbf{1 1}$ & $\mathbf{2 1}$ & $\mathbf{8}$ & $\mathbf{2 1}$ & $\mathbf{3 4}$ & $\mathbf{2 6}$ & $\mathbf{2 5}$ & $\mathbf{2 8}$ & $\mathbf{1 8}$ & $\mathbf{2 7}$ & $\mathbf{2 4}$ & $\mathbf{2 0}$ & $\mathbf{1 9}$ & $\mathbf{1 4}$ & $\mathbf{2 9}$ & $\mathbf{3 1}$ & $\mathbf{2 2}$
\end{tabular}

Table 2. Comparison of MPX failures in incidents and port MPX compliance.

\begin{tabular}{|c|c|c|c|c|c|c|c|c|c|c|c|c|c|c|c|c|c|c|}
\hline Theme/Port & Generic & A & B & $\mathrm{C}$ & $\mathrm{D}$ & $\mathrm{E}$ & $\mathrm{F}$ & G & $\mathrm{H}$ & I & $\mathrm{J}$ & $\mathrm{K}$ & $\mathrm{L}$ & M & $\mathrm{N}$ & $\mathrm{O}$ & $\mathrm{P}$ & Compliance \\
\hline Pass Plan agreement*** & & & $\checkmark$ & & & $\checkmark$ & $\checkmark$ & & & & $\checkmark$ & & & & & $\checkmark$ & $\checkmark$ & $38 \%$ \\
\hline Manning requirements** & $\checkmark$ & & & & & & & & & & $\checkmark$ & $\checkmark$ & & & & & $\checkmark$ & $25 \%$ \\
\hline Language requirements** & & & & & & $\checkmark$ & & & $\checkmark$ & & & & & & & & & $13 \%$ \\
\hline Indicative Route* & $\checkmark$ & $\checkmark$ & $\checkmark$ & & $\checkmark$ & & & $\checkmark$ & & $\checkmark$ & $\checkmark$ & $\checkmark$ & & $\checkmark$ & & & $\checkmark$ & $63 \%$ \\
\hline Speed limits* & & & & & $\checkmark$ & & & $\checkmark$ & & & & $\checkmark$ & & & & & $\checkmark$ & $25 \%$ \\
\hline Abort point agreement* & $\checkmark$ & & & & & $\checkmark$ & & & $\checkmark$ & $\checkmark$ & & & & & & & & $25 \%$ \\
\hline Visibility assessment* & & & & & & & & & $\checkmark$ & & & & & $\checkmark$ & & & & $13 \%$ \\
\hline Manoeuvre agreement* & & & & & & $\checkmark$ & & & & $\checkmark$ & & & & & & & & $13 \%$ \\
\hline
\end{tabular}

*** Denotes theme features in all three investigation reports.

** Denotes theme features in two investigation reports.

* Denotes theme failure in only one investigation report. 
identified in the three investigations, but 33 which are neutral. The average port MPX compliance ranges from $60 \%$ (one attribute) to $13 \%$ (three attributes, or just one in eight ports). A significant amount of time could be taken up recording information, such as the name of the ship's agent, that will have no bearing on the outcome of the planned act of pilotage.

6. CONCLUSIONS. Without question, it is important that certain technical information, such as the minimum under keel clearance (UKC) and tidal information, is recorded on the Master Pilot Exchange (MPX) form. It is also clear that a document does not, and cannot, replace the face-to-face verbal discussion that must take place between the Master and the Pilot. Indeed, much depends upon this. Rapport and teamwork can never be supplanted by paperwork. However, it is evident that many of the MPX forms in use today in UK ports do not direct Masters and Pilots to discuss, and agree, potential critical points of failure during the proposed act of pilotage. Much of the faithfully recorded information has no bearing on the outcome of the passage. It could be argued that, in fact, time that should be spent on those discussions is wasted on noting extraneous information such as the port security level and the number of persons on board the ship. It is also evident that the design of documentation needs to be improved so that the Pilot is directed to record critical information logically and sequentially, thus addressing substantive themes/areas that should be verbally discussed and, most importantly, agreed.

Further research is required to establish that the findings from this UK study are replicated internationally. Research notwithstanding; it is likely that, from port to port, the Master of a ship is faced with a plethora of MPX forms, all with different designs and emphases. MPX forms may be effective in directing discussions, and agreement, on local navigational issues, but the Master and Pilot must address critical aspects which are common to any, and every, passage plan. A more unified approach will make this task easier and more effective, thus increasing the value of the information exchange documentation.

\section{ACKNOWLEDGEMENTS}

The authors are grateful to the UK ports who participated in the provision of port MPX forms.

\section{REFERENCES}

IGP\&I (2004). Pilotage Sub-committee. Report on pilot error related claims. London. International Group of P\&I Clubs.

International Chamber of Shipping (2007). Bridge Procedures Guide. London. Marisec Publications.

Intertanko, OCIMF and ICS, (2002). International Best Practices for Maritime Pilotage.

MAIB (1997). Sea Empress Investigation Report. Southampton. HMSO.

MAIB (2008). Sichem Melbourne Investigation Report. Southampton. HMSO.

MAIB (2009). Vallermosa Investigation Report. Southampton. HMSO.

Murdoch, E., Clark, C., Dand, I. and Glover, B. (2004). A Master's Guide to Berthing. London. Charles Taylor \& Co. Ltd. The Standard P\&I Club.

USCG (2009). Report of the Collision between the Cosco Busan and the San Francisco-Oakland Bay Bridge. Washington. USCG.

Wiener, E. (1993). Intervention Strategies for the Management of Human Error. Coral Gables, University of Miami. 